\title{
Cultured cambial meristematic cells - a sustainable route towards in vitro production of phytochemicals.
}

\author{
Hemant Sood* \\ Department of Biotechnology \& Bioinformatics, Jaypee University of Information Technology, India
}

Accepted on January 12, 2017

Plant-derived natural products or secondary metabolites attract a great deal of attention pertaining to their structure, synthesis and production of wide variety of economically important products, such as flavors, fragrances, pigments, dyes, fine chemicals, cosmetics, nutraceuticals, drugs and pharmaceuticals. Most common approach for obtaining these compounds is from their native source i.e. plants. However, this conventional process presents a number of disadvantages such as non-availability of these metabolites from plants throughout year, difficulty in plant cultivation and inconsistent product yield due to climatic variations. Difficulty to obtain sufficient amounts of desired plant material, their slow growth, varying composition and concentration depending upon the geographical position and climatic conditions coupled with low yield of isolated compounds are some of the limitations of commercial extraction of these compounds by using plants as a single resource $[1,2]$.

The reckless collection of plants has put several of them under the categories of endangered or at the verge of extinction. This has prompted industries and scientists to find alternative technologies for the production of plant natural products so that the natural habitat of plants can be preserved.

Plant cell cultures offer alternate to production of valuable phytochemicals, however, the success rate has been very low as of today. Only countable natural products have been produced commercially through plant cell cultures. For example the production of berberine from Coptis japonica by Mitsui Petrochemicals [2] and production of paclitaxel from different species of Taxus 3 are notable case studies. The Paclitaxel supply in the USA is met by a plant cell culture technology with its proven feasibility by Bristol-Meyers Squibb and Phyton Biotech, Inc. In addition, the Samyang Genex has also commercialized a process for the production of paclitaxel via plant cell culture [3-5]

Ever since the beginnings of tissue culture in the 1940s, cell suspension cultures were routinely generated from callusderived dedifferentiated cells (DDCs), which encountered several problems in consistent and stable production of natural products. The suspension cultures derived from callus cultures exhibit poor growth properties with low and inconsistent yields of natural products, owing to not only deleterious genetic and epigenetic changes that occur during the culture process but also incompatibility of these cell cultures to upscale processes in bioreactors.

Culturing of innately undifferentiated cambial meristematic cells (CMCs) of Taxus cuspidata, the source of the key anticancer drug, paclitaxel (Taxol) has provided new hope towards in vitro production of phytochemicals. Vascular cambium is a very thin layer of cells that lie between the primary xylem and primary phloem They contain meristematic cells that produce secondary xylem and phloem. The vascular cambium is located in the stems and roots of dicot plants and gymnosperms. Stem cells function as reserves of undifferentiated cells to replace tissues and sustain growth in both animals and plants. Stem cell niches are functionally similar in plants and animals, probably because of convergent evolution. The best studied stem cell niches in plants are located in the shoot and root meristems, which are the ultimate source of virtually all post-embryonic shoot and root tissues.

To circumvent this so-called dedifferentiation procedure, Lee developed an innately undifferentiated cell line derived from cambium cells, which function as vascular stem cells [5]. The potential and universality of this technology to produce CMCs was demonstrated from a variety of plant species, including ginseng (Panax ginseng), ginkgo (Ginkgo biloba) and tomato (Solanum lycopersicon, suggesting that the procedure has broad utility. The potential of CMCs in in vitro production of paclitaxel was demonstrated for their abilities to produce significantly higher amounts of paclitaxel over conventional callus-derived dedifferentiated cells (DDCs) for various production parameters [5].

The amount of paclitaxel produced by CMCs, $102 \mathrm{mg} / \mathrm{kg}$ fresh cell weight (f.c.w.), was conspicuously greater than that generated by either needle or embryo-derived DDCs at a f.c.w. value of $23 \mathrm{mg} / \mathrm{kg}$ or $39 \mathrm{mg} / \mathrm{kg}$, respectively [5]. Lee [5] also determined the level of paclitaxel production of these different $\mathrm{T}$ cuspidata cell suspensions in both 3 liter and 20 liter air-lift bioreactors. At $10 \mathrm{~d}$ after elicitation, CMCs again synthesized strikingly more paclitaxel than either of the DDC lines in a 3 liter air-lift bioreactor. Further, elicitation induced a 220\% (11 $\mathrm{mg} / \mathrm{kg}$ ) and $433 \%$ (13 mg/kg) increase in paclitaxel production within needle- and embryo-derived DDCs respectively, whereas the induction was $14,000 \%(98 \mathrm{mg} / \mathrm{kg})$ with CMCs. CMCs secreted $2.7 \times 104 \%$ and $7.2 \times 104 \%$ more paclitaxel into the culture medium than the low levels secreted by either needle- or embryo-derived DDCs, respectively $[5,6]$.

The significantly higher yields of paclitaxel coupled with the stability of CMCs in their production potential even at the bioreactor scale provides immense opportunities to plant scientists, both in academia and industry, to utilize this technology for optimizing conditions for the in vitro production of natural products in plant species, which are endangered. CMCs are, therefore, expected to provide a cost-effective, environmentally friendly and sustainable source of paclitaxel and potentially other important plant natural products. Unlike plant cultivation, this approach is not subject to the unpredictability caused by variation in climatic conditions or political instability in certain parts of the world. 


\section{References}

1. Payne GF, Bringi V, Prince V, et al. Plant Cell and Tissue Culture in Liquid Systems. New York: Hanser Publishers 1991; $1: 29-5$.

2. Morimoto. Agricultural and Biological Chemistry 1988;52:1835-6.

3. Tabata H. Primary Mural Endocarditis without valvular involvement. Advances in Biochem Engin/Biotechnol 2004;87:1-23.
4. Zhong J. Sequence and analysis of chromosome 4 of the plant Arabidopsis thaliana. Journal of Bioscience. Bioengineering 2002;94:591-9.

5. Lee JH. Global and local fMRI signals driven by neurons defined optogenetically by type and wiring. Nature Biotechnology 2010;28:1213-7.

6. Wang C. Activity Studies of Immobilized Subtilisin on Functionalized Pure Cellulose-Based Membranes. Biotechnology Progress 2001;17:89-4.

\section{*Correspondence to:}

Dr. Hemant Sood

Assistant Professor (Senior Grade)

Department Of Biotechnology and Bioinformatics Jaypee University of Information Technology Waknaghat

Solan

India

173234 